\title{
Preparation of Acicular Mesoporous Char Sulfonic Acid and Its Application for Conversion of Fructose to 5- Hydroxymethylfurfural
}

\author{
Shuang Zhang, ${ }^{\mathrm{a}}$ Xiaohui Han, ${ }^{\mathrm{b}}$ Yanjie Liu, ${ }^{\mathrm{a}, *}$ Ling Liu, ${ }^{\mathrm{a}}$ Jiajun Yang, ${ }^{\mathrm{a}}$ and Long Zhang ${ }^{\mathrm{c}, *}$ \\ Acicular mesoporous char sulfonic acid was prepared through a one-step \\ method of removing the template at the same time of sulfonation using \\ ethylene $\operatorname{tar}(\mathrm{ET})$ as the carbon source and acicular nanometer \\ magnesium hydroxide as the hard template. This method was judged as \\ better than the two-step method of removing the template before \\ sulfonation because it protected the mesoporous structure from damage \\ to a certain extent. When the mass ratio of ET to $\mathrm{Mg}(\mathrm{OH})_{2}$ was $1: 3$ and \\ carbonization temperature was $550{ }^{\circ} \mathrm{C}$, the catalyst prepared using the \\ one-step method had the highest activity. The obtained catalyst had an \\ amorphous structure with a specific surface area of $446.5 \mathrm{~m}^{2} / \mathrm{g}$, an acid \\ density of $4.68 \mathrm{mmol} / \mathrm{g}$, and an average pore diameter of $3.5 \mathrm{~nm}$. When \\ the catalyst was applied in the dehydration of fructose to synthesize 5- \\ hydroxymethylfurfural (5-HMF), 97.5\% fructose conversion and $80.1 \% 5$ - \\ HMF yield can be obtained. The activity of the catalyst did not decrease \\ after 5 cycles, which indicated that the catalyst had good stability. This \\ research provides a promising strategy for preparation of mesoporous \\ char sulfonic acid and comprehensive utilization of ET.
}

Keywords: Fructose; 5-hydroxymethylfurfural; Ethylene tar; Acicular magnesium hydroxide; Mesoporous char sulfonic acid

Contact information: a: Institute of Petrochemical Technology, Jilin Institute of Chemical Technology, No. 45 Chengde Street, Jilin 132022, China; b: CNPC East China Design Institute Co. Ltd., Jilin Branch, Jilin 132022, China; c: School of Chemical Engineering, Changchun University of Technology, No. 2055 Yanan Street, Changchun 130012, China; *Corresponding author: zhanglongzhl@163.com

\section{INTRODUCTION}

Non-renewable petrochemical resources are facing depletion. An effective way to solve this problem is to replace the petrochemical resources with renewable biomass resources (Liguori et al. 2019). 5-hydroxymethylfurfural (5-HMF) is an important renewable biomass platform organic compound that has the structure of aromatic alcohol and aromatic aldehyde in the furan ring system (Rosatella et al. 2011). It has high reactivity and can be used to synthesize a variety of high value-added chemicals, including 2,5furandicarboxylic acid, 2,5-dimethylfuran, and levulinic acid (Thananatthanachon and Rauchfuss 2010; Zhang et al. 2012; Hayashi et al. 2019). A large number of studies have shown that fructose can be used to synthesize 5-HMF under the action of an acid catalyst (Dutta et al. 2013; Saha and Abu-Omar 2014; Wang et al. 2019). Solid acids as heterogeneous acids have been widely used in this reaction because they can be easily separated from the reaction solution and recycled (Shimizu et al. 2009; Yang et al. 2010; Karimi et al. 2015).

One type of solid acid, carbon-based solid acid, has the advantages of high acid density, rich Brønsted acid active center, and strong binding force between the sulfonic 
acid functional group and matrix material (Kitano et al. 2009; Malins et al. 2015; Farabi et al. 2019). Hara et al. (2004) reported the sulfonation of naphthalene or anthracene with concentrated sulfuric acid (Hara et al. 2004). The obtained black powdered carbon-based sulfonic acid was insoluble in water, benzene, methanol, ethanol, and n-hexane. It is composed of aromatic carbon rings arranged irregularly, its acid density was found to be $4.90 \mathrm{mmol} / \mathrm{g}$, and its specific surface area was measured as $24 \mathrm{~m}^{2} / \mathrm{g}$. The catalyst was used in hydrolysis and esterification, its activity was higher than that of $\mathrm{Nb}_{2} \mathrm{O}_{5}$ and Nafion, and close to that of sulfuric acid. Later, Toda et al. (2005) reported a new type of "sugar catalyst", which was based on sucrose or glucose. It was made through high-temperature polycondensation and cracking reactions to obtain polycyclic aromatic hydrocarbons, then sulfonation with concentrated sulfuric acid to obtain amorphous carbon-based sulfonic acid with rich phenol and carboxyl groups on the surface (Toda et al. 2005). It was applied to the deacidification of high acid value oil, and the catalytic activity was more than half that of liquid sulfuric acid. In addition, the catalyst had good thermal stability, even if it was used repeatedly at 80 to $180{ }^{\circ} \mathrm{C}$, and there was no loss of activity. Tanemura et al. (2011, 2012) prepared condensed polynuclear aromatic resin (COPNA) through naphthalene, pyrene, or phenanthrene as raw materials, $\mathrm{p}$-dimethylbenzene or p-benzaldehyde as crosslinking agent, p-toluenesulfonic acid as the catalyst, and then sulfonated the resin to obtain carbon-based solid acid (S-COPNA). Daengprasert et al. (2011) prepared naphthalene into solid sulfonic acid with the specific surface area of $1.1 \mathrm{~m}^{2} / \mathrm{g}$ and the acid density of 1.46 $\mathrm{mmol} / \mathrm{g}$, which was used for the hydrolysis of cassava residue in the mixed solvent of dimethyl sulfoxide/acetone-water. The yield of 5-HMF was $12.1 \%$ (Daengprasert et al. 2011). Carbon-based solid acids prepared from polycyclic aromatic hydrocarbons generally have low specific surface area and almost no pore structure. Increasing the specific surface area can increase the probability of collision of reactants and the internal active center of the catalyst.

Generally, silica as the hard template has been commonly used to increase the specific surface area of carbon-based solid acid. To remove it, hydrofluoric acid solution with strong corrosiveness was needed. There are still some problems in the preparation of carbon-based solid acid with silica as the template. For example, if the template is removed before sulfonation, the mesoporous structure of the catalyst will be destroyed in the process of sulfonation (Janaun and Ellis 2011). If the template is removed after sulfonation, the carbon precursor becomes filled in the pores of the silica, which makes the gap between the carbon and silica smaller. In the sulfonation reaction, it was difficult for the sulfonic acid functional groups to connect to the carbon skeleton, resulting in the lower acid density of the catalyst (Peng et al. 2010). Therefore, for the optimization of the mesoporous structure of carbon-based solid acid, it is necessary to develop hard templates that are easy to remove and to consider the removal methods of hard templates. Zhang et al. (2012) reported that acicular nanometer magnesium hydroxide can be used as a hard template to prepare mesoporous carbon materials with high specific surface area. Under high temperature calcination, magnesium hydroxide was converted into magnesium oxide, which can be removed by sulfuric acid. So, using magnesium hydroxide as a hard template to prepare carbon-based solid acid is able to simultaneously remove the template and achieve sulfonation.

In addition, most carbon-based solid acids are made from polycyclic aromatic hydrocarbons or biomass through incomplete carbonization and sulfonation (Budarin et al. 2006; Zhang et al. 2015). Due to the high price of raw materials or complex preparation of precursor, the large-scale industrial production of carbon-based solid acids is limited. 
Therefore, it is necessary to consider inexpensive and easily available raw materials and find a simple preparation process.

Ethylene tar (ET) is a by-product of the ethylene industry. It is cheap and rich in non-side chain and short side chain condensed aromatic hydrocarbons (Ge et al. 2016). In this work, ethylene tar was used as the carbon source, and acicular nanometer magnesium hydroxide served as the hard template. The acicular mesoporous char sulfuric acid was prepared by removing the template at the same time as sulfonation. The effects of mass ratio of ET to hard template and the effects of carbonization temperature on specific surface area, acid content, and pore structure of catalyst were evaluated. The catalyst was applied in the dehydration of fructose to synthesize 5-HMF, the activity and stability of the catalyst were investigated. Therefore, the bridge between carbohydrate biomass resources and petrochemical resources can be established with fructose as the raw material, while solving the problem of post-treatment for the ethylene industry (Fig. 1).

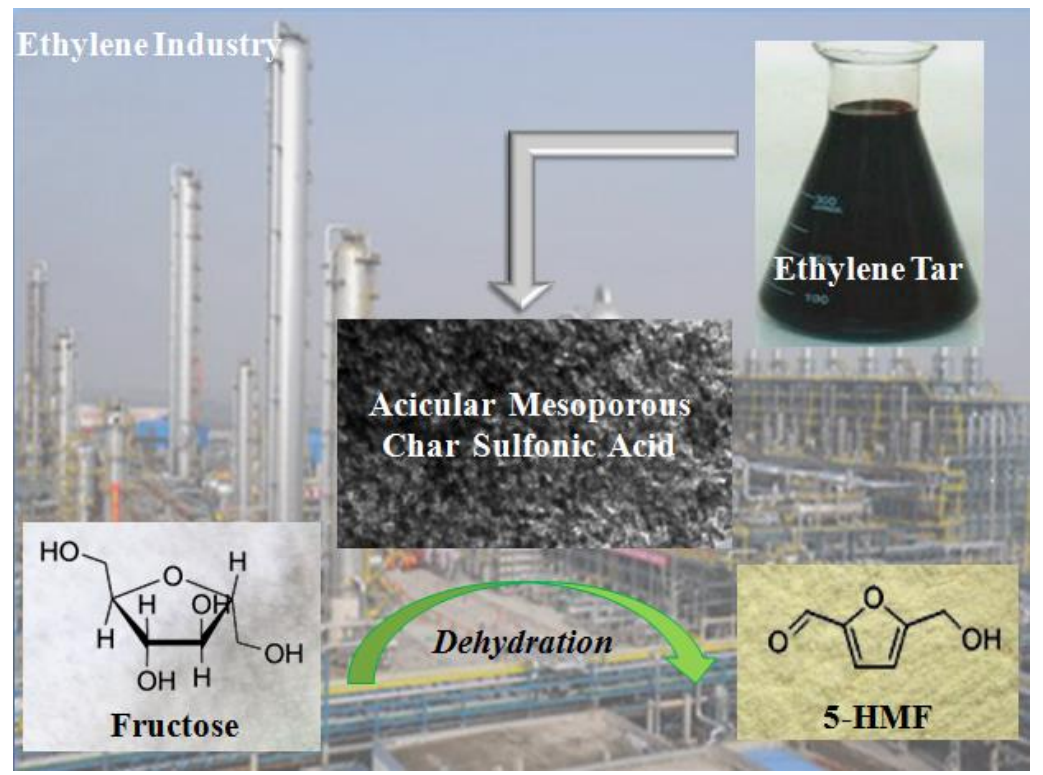

Fig. 1. Acicular mesoporous char sulfonic acid was used for the dehydration of fructose to synthesize 5-HMF

\section{EXPERIMENTAL}

\section{Materials}

Fructose, 5-hydroxymethylfurfural (5-HMF), polyvinyl pyrrolidone (PVP K30, average molecular weight $40000 \mathrm{~g} / \mathrm{mol}$ ), and polyvinyl pyrrolidone (average molecular weight 360,000 g/mol) were purchased from Sigma-Aldrich reagent Co., Ltd., Shanghai, China. Isopropyl alcohol was purchased from Aladdin reagent Co., Ltd., Shanghai, China. Concentrated sulfuric acid, sodium hydroxide, magnesium chloride hexahydrate, and potassium oleate were purchased from Beijing Chemicals Co., Ltd., Beijing, China. Ethylene tar (ET) was obtained from PetroChina Co., Ltd., Jilin, China.

\section{Preparation of acicular nanometer magnesium hydroxide}

Under the action of ultrasound, $20.0 \mathrm{~g}$ of magnesium chloride hexahydrate, $0.25 \mathrm{~g}$ of polyvinylpyrrolidone (average molecular weight was 360000 ), and $1.0 \mathrm{~g}$ of potassium 
oleate were dissolved in $10 \mathrm{~mL}$ of water, respectively. Then they were slowly mixed into a flask with three necks (Qiu et al. 2003). The flask was placed in a low temperature circulating water bath at $10 \pm 0.5^{\circ} \mathrm{C}$. With violent stirring, $2.0 \mathrm{M} \mathrm{NaOH}$ was dropped into the solution with a peristaltic pump until the $\mathrm{pH}$ value reached 10 , and the flow rate of dropping $\mathrm{NaOH}$ controlled at $2.0 \mathrm{~mL} / \mathrm{min}$. With violent stirring, the white suspension generated was aged for $1 \mathrm{~h}$. Magnesium hydroxide was washed repeatedly with deionized water and dried in vacuum at $50{ }^{\circ} \mathrm{C}$ for $8 \mathrm{~h}$.

\section{Preparation of acicular mesoporous char sulfonic acid}

The ET was vacuum distilled to remove light fraction $\left(<250{ }^{\circ} \mathrm{C}\right)$. The obtained heavy fraction and acicular nanometer magnesium hydroxide was ground evenly according to a certain mass ratio ET to $\mathrm{Mg}(\mathrm{OH})_{2}$. The mixture was put into a tubular furnace and heated to a certain temperature $\left(400\right.$ to $\left.600{ }^{\circ} \mathrm{C}\right)$ in nitrogen atmosphere at a heating rate of $5^{\circ} \mathrm{C} / \mathrm{min}$ and maintained for $1 \mathrm{~h}$. The carbonized product was sulfonated with concentrated sulfuric acid at $150{ }^{\circ} \mathrm{C}$ in the nitrogen atmosphere for $15 \mathrm{~h}$, and the hard template was removed at the same time of sulfonation (One-step method). The ratio of the carbonized product $(\mathrm{g})$ and concentrated sulfuric acid $(\mathrm{mL})$ was 1:10. Acicular mesoporous char sulfonic acid was washed with hot water at $80^{\circ} \mathrm{C}$ until the filtrate was neutral, and dried in vacuum at $80{ }^{\circ} \mathrm{C}$ for $12 \mathrm{~h}$, which was named carbonization temperature-catalyst-1.

To compare with the catalyst prepared by the two-step method of removing the template before sulfonation, the hard template was first removed from the carbonized product with $2.0 \mathrm{M}$ dilute sulfuric acid, and then washed and dried. Finally, materials obtained were sulfonated with concentrated sulfuric acid, which was named carbonization temperature-catalyst-2. The remaining steps were the same as one-step method. The preparation flowchart of mesoporous char sulfonic acid is shown in Fig. 2.

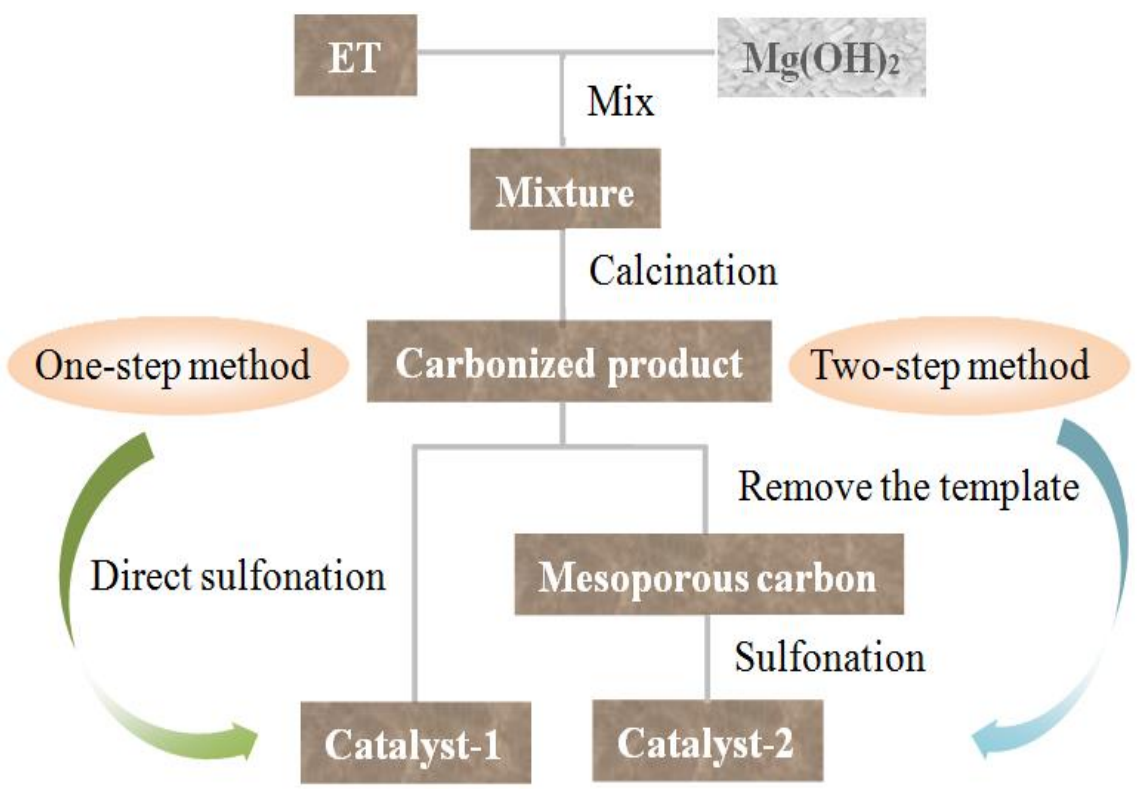

Fig. 2. Preparation flowchart of mesoporous char sulfonic acid

\section{Dehydration of fructose}

$0.5 \mathrm{~g}$ fructose, $0.25 \mathrm{~g}$ catalyst, $7 \mathrm{ml}$ isopropanol, and $0.2 \mathrm{~g}$ polyvinyl pyrrolidone K-30 (PVP K-30) were added into the reactor. The mixture was heated to $130{ }^{\circ} \mathrm{C}$ and 
maintained for $140 \mathrm{~min}$. After the reaction finished, the catalyst was filtered out. The composition of the filtrate was determined by HPLC. The yield and selectivity of 5-HMF and the conversion of fructose were calculated.

\section{Methods}

Catalysts characterization

The functional groups of samples were checked via a Nicolet 6700 Fourier transform infrared (FT-IR) spectrometer (Thermo Fisher Scientific Co., Ltd., Shanghai, China).

The phase structures of samples were identified by X-ray diffraction (XRD) on a Rigaku D/max-2500 X-ray diffractometer (Rigaku Corporation, Tokyo, Japan) with CuKa radiation $(\lambda=0.1542 \mathrm{~nm})$.

The specific surface areas and pore size distributions of samples were measured by $\mathrm{N}_{2}$ adsorption-desorption on a micromeritics TriStar II (micromeritics Co., Ltd., Shanghai, China).

The mesoporous morphology of samples was recorded by transmission electron microscopy (TEM) using JEM-2000EX instrument (JEOL Co., Ltd., Tokyo, Japan) with an accelerating voltage of $200 \mathrm{kV}$.

\section{RESULTS AND DISCUSSION}

\section{Effects of Mass Ratio of ET to $\mathrm{Mg}(\mathrm{OH})_{2}$}

When the carbonization temperature was $500{ }^{\circ} \mathrm{C}$, the effects of the mass ratio of ethylene tar and acicular magnesium hydroxide on the specific surface area, acid density, and 5-HMF yield were investigated. The results are shown in Table 1.

Table 1. Effects of Mass Ratio of ET to $\mathrm{Mg}(\mathrm{OH})_{2}$

\begin{tabular}{|c|c|c|c|c|c|c|c|}
\hline \multirow{3}{*}{$\begin{array}{c}\text { Mass Ratio } \\
\text { of ET to } \\
\mathrm{Mg}(\mathrm{OH})_{2}\end{array}$} & \multicolumn{3}{|c|}{ Specific Surface Area $\left(\mathrm{m}^{2} / \mathrm{g}\right)$} & \multirow{2}{*}{\multicolumn{2}{|c|}{$\begin{array}{c}\text { Acid Density } \\
(\mathrm{mmol} / \mathrm{g})\end{array}$}} & \multirow{2}{*}{\multicolumn{2}{|c|}{$\begin{array}{c}\text { Yield of 5-HMF } \\
(\%)\end{array}$}} \\
\hline & \multirow{2}{*}{$\begin{array}{c}\text { Before } \\
\text { Sulfonation }\end{array}$} & \multicolumn{2}{|c|}{ After Sulfonation } & & & & \\
\hline & & $\begin{array}{l}\text { One- } \\
\text { step }\end{array}$ & $\begin{array}{l}\text { Two- } \\
\text { step }\end{array}$ & $\begin{array}{l}\text { One- } \\
\text { step }\end{array}$ & $\begin{array}{l}\text { Two- } \\
\text { step }\end{array}$ & $\begin{array}{l}\text { One- } \\
\text { step }\end{array}$ & $\begin{array}{l}\text { Two } \\
\text { step }\end{array}$ \\
\hline $1 / 1$ & 226.9 & 105.4 & 88.0 & 3.31 & 3.25 & 52.4 & 50.8 \\
\hline $1 / 2$ & 335.2 & 252.4 & 137.3 & 3.96 & 3.44 & 59.2 & 53.9 \\
\hline $1 / 3$ & 487.3 & 356.1 & 141.0 & 4.22 & 3.49 & 65.9 & 55.3 \\
\hline $1 / 4$ & 329.9 & 270.5 & 119.6 & 4.13 & 3.38 & 63.7 & 52.3 \\
\hline $1 / 5$ & 290.5 & 146.4 & 60.0 & 3.52 & 3.10 & 55.6 & 49.2 \\
\hline
\end{tabular}

Before sulfonation: Removal of hard template with $2 \mathrm{M}$ dilute sulfuric acid

Table 1 shows that with the decrease of mass ratio of ET and acicular magnesium hydroxide, the specific surface area of carbonized product after removing the template increased first and then decreased, which indicated that increasing the amount of acicular magnesium hydroxide was conducive to improving the specific surface area of carbonized product. However, an excessive amount of acicular magnesium hydroxide may have interweaved to form larger pores, which may have led to the decrease of specific surface area. Compared with the specific surface area of carbonized product before sulfonation, the specific surface area of catalyst after sulfonation was remarkably reduced in both the one-step and two-step methods. The main reason for this phenomenon was the collapse of pores caused by sulfonation. It was found that the specific surface area of the catalyst 
prepared by the one-step method was larger than that by the two-step method, which indicated that the one-step method of removing the template at the same time of sulfonation can protect the mesoporous structure from damage to some extent.

The variation of acid density was consistent with the variation of specific surface area. Under the same carbonization temperature, high specific surface area was beneficial to increase the binding sites between $\mathrm{SO}_{3} \mathrm{H}$ functional groups and carbonized product, to increase the acid density of the catalyst.

The 5-HMF yield achieved by the one-step method was higher than that by the twostep method, because the specific surface area and acid density of the catalyst prepared by the one-step method were higher than that by the two-step method. It was obvious that the activity of the catalyst was related to the specific surface area and acid density of the catalyst when the carbonization temperature was the same. When the mass ratio of ET to acicular magnesium hydroxide was 1:3, the specific surface area, acid density, and catalytic activity of the catalyst prepared by the one-step method were the highest, which were 356.1 $\mathrm{m}^{2} / \mathrm{g}, 4.22 \mathrm{mmol} / \mathrm{g}$, and $65.9 \%$, respectively.

\section{Effects of Carbonization Temperature}

When the mass ratio of ET to acicular magnesium hydroxide was 1:3, the effects of carbonization temperature on the specific surface area, acid density, and 5-HMF yield were investigated. The results are shown in Table 2 . The catalyst prepared by one-step method was named catalyst-1, the catalyst prepared by two-step method was named catalyst-2.

Table 2. Effects of Carbonization Temperature

\begin{tabular}{|c|c|c|c|c|c|c|c|}
\hline \multirow{3}{*}{$\begin{array}{c}\text { Carbonization } \\
\text { Temperature } \\
\left({ }^{\circ} \mathrm{C}\right)\end{array}$} & \multicolumn{3}{|c|}{ Specific Surface Area $\left(\mathrm{m}^{2} / \mathrm{g}\right)$} & \multirow{2}{*}{\multicolumn{2}{|c|}{$\begin{array}{c}\text { Acid Density } \\
(\mathrm{mmol} / \mathrm{g})\end{array}$}} & \multirow{2}{*}{\multicolumn{2}{|c|}{$\begin{array}{c}\text { 5-HMF Yield } \\
(\%)\end{array}$}} \\
\hline & \multirow{2}{*}{$\begin{array}{c}\text { Before } \\
\text { Sulfonation }\end{array}$} & \multicolumn{2}{|c|}{ After Sulfonation } & & & & \\
\hline & & $\begin{array}{l}\text { One- } \\
\text { step }\end{array}$ & $\begin{array}{l}\text { Two- } \\
\text { step }\end{array}$ & $\begin{array}{l}\text { One- } \\
\text { step }\end{array}$ & $\begin{array}{l}\text { Two- } \\
\text { step }\end{array}$ & $\begin{array}{l}\text { One- } \\
\text { step }\end{array}$ & $\begin{array}{l}\text { Two- } \\
\text { step }\end{array}$ \\
\hline 400 & 306.6 & 220.3 & 88.3 & 3.65 & 3.24 & 59.2 & 46.1 \\
\hline 450 & 395.9 & 306.4 & 126.5 & 4.00 & 3.44 & 61.7 & 55.0 \\
\hline 500 & 487.3 & 356.1 & 141.0 & 4.22 & 3.49 & 65.9 & 55.3 \\
\hline 550 & 643.4 & 446.5 & 217.4 & 4.68 & 3.85 & 80.1 & 69.5 \\
\hline 600 & 751.9 & 578.3 & 402.4 & 4.03 & 3.63 & 75.4 & 64.6 \\
\hline
\end{tabular}

Before sulfonation: Removal of hard template with $2 \mathrm{M}$ dilute sulfuric acid

Table 2 shows that with the increase of carbonization temperature, the specific surface area of the mesoporous carbon and catalyst increased gradually. It can be concluded that increasing the carbonization temperature was beneficial to increasing the specific surface area. The carbonization temperature was in the range of 400 to $600{ }^{\circ} \mathrm{C}$, and the specific surface area and pore size distribution of catalyst-1 were measured by $\mathrm{N}_{2}$ adsorption/desorption, as shown in Fig. 3. It can be seen from Fig. 3 (a through e) that the adsorption/desorption isotherms were typical IV type, and the adsorption/desorption hysteresis loop were typical $\mathrm{H}_{2}$ type, which occurred in the range of relative pressure $\left(P / P_{0}\right)$ of approximately 0.4 to 0.8 . The specific surface area of the catalyst was in the range of 400 to $600{ }^{\circ} \mathrm{C}$ were $220.3,306.4,356.1,446.5$, and $578.3 \mathrm{~m}^{2} / \mathrm{g}$. Figure 3 (f through $\mathrm{j}$ ) shows the pore size distribution diagram. When the carbonization temperature was $400{ }^{\circ} \mathrm{C}$, the average pore size of the catalyst was $3.6 \mathrm{~nm}$, and when the carbonization temperature was 450 to $600{ }^{\circ} \mathrm{C}$, the average pore size of the catalyst was $3.5 \mathrm{~nm}$. 

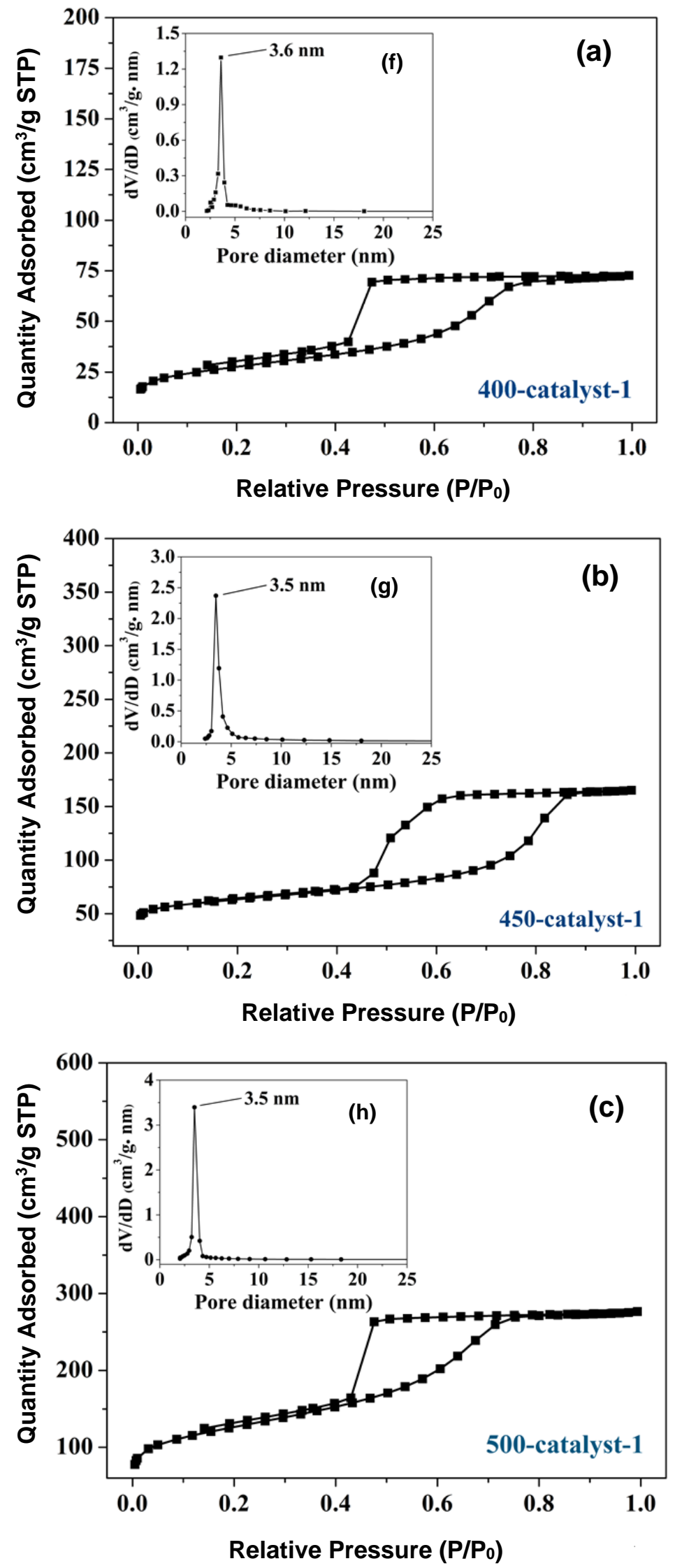

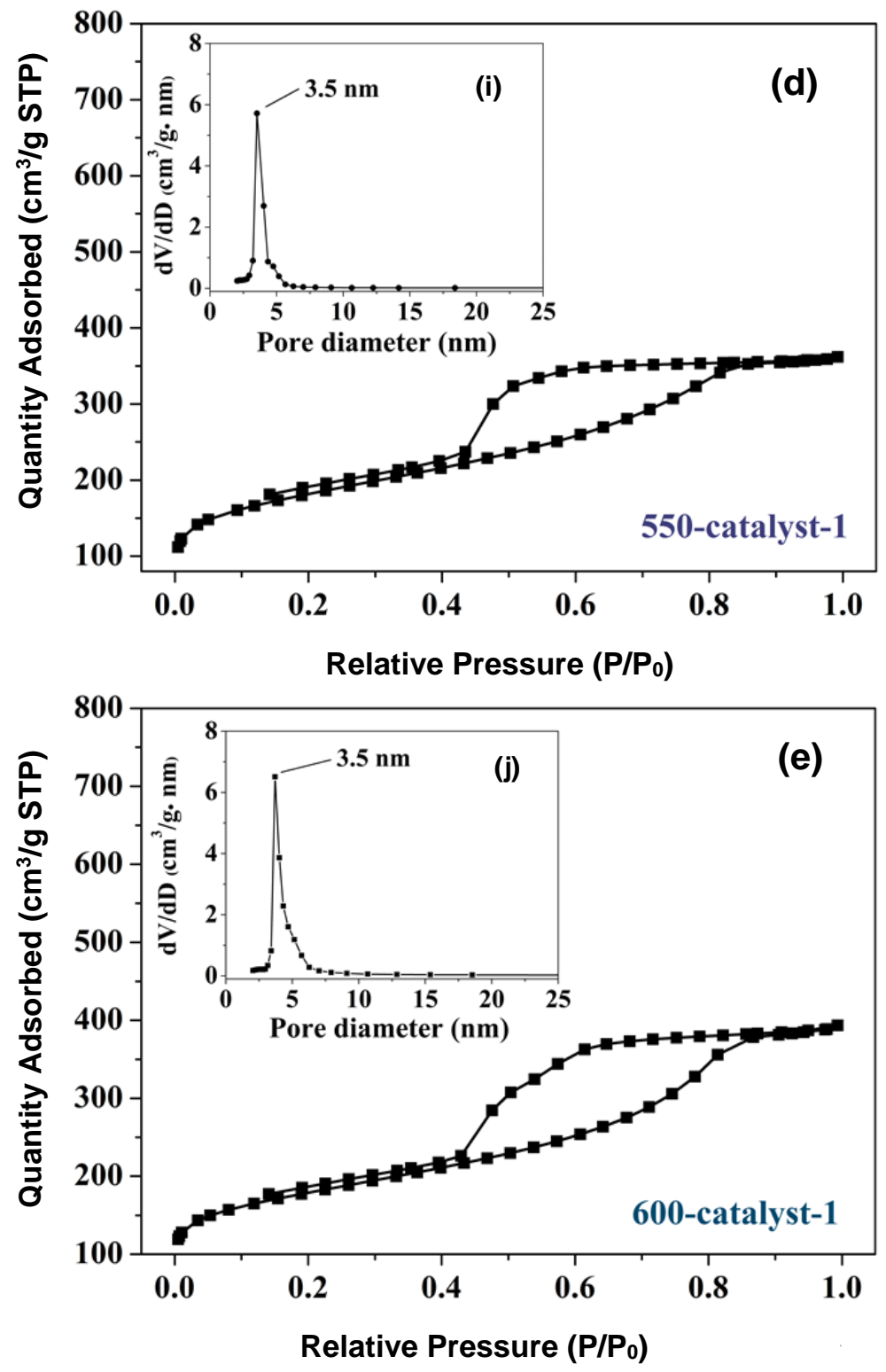

Fig. 3. (a through e) $\mathrm{N}_{2}$ adsorption/desorption isotherm and (f-j) BJH pore size distribution plot of acicular mesoporous char sulfonic acid

With the increase of carbonization temperature, for both the one-step method and two-step method, the acid density of the catalyst increased first and then decreased. At the same carbonization temperature, the acid density of catalyst- 1 was higher than that in catalyst-2. When the carbonization temperature was over $550{ }^{\circ} \mathrm{C}$, the acid density decreased despite increasing the specific surface area. High carbonization temperature led to more $\mathrm{C}-\mathrm{H}$ bond breakage, forming $\mathrm{C}-\mathrm{C}$ bonds, and $\mathrm{C}=\mathrm{C}$ bonds (Wang et al. 2011). The aromatic rings compounds with smaller molecular weight polymerized into the aromatic ring compounds with larger molecular weight; the gradual graphitization reduced the vacancy, which can be replaced by sulfonic acid functional groups, so it was not conducive to sulfonation (Wang et al. 2011). Therefore, when the carbonization temperature was 550 ${ }^{\circ} \mathrm{C}$, the catalyst prepared by the one-step method had the highest acid density (4.68 
$\mathrm{mmol} / \mathrm{g})$, higher specific surface area $\left(446.5 \mathrm{~m}^{2} / \mathrm{g}\right)$, and the 5 -HMF yield was $80.1 \%$. Moreover, as shown in Table 2, the variation of catalytic activity was consistent with the variation of acid density at the same carbonization temperature. In addition, the specific surface area of catalyst- 1 was $220.3 \mathrm{~m}^{2} / \mathrm{g}$ at $400{ }^{\circ} \mathrm{C}$, and that of catalyst- 2 was $217.4 \mathrm{~m}^{2} / \mathrm{g}$ at $550{ }^{\circ} \mathrm{C}$; however, the acid density and 5-HMF yield of catalyst- 2 were higher than those of catalyst-1. This is because the specific surface area of mesoporous carbon obtained from $550{ }^{\circ} \mathrm{C}$ was much higher than the specific surface area of mesoporous carbon obtained from $400{ }^{\circ} \mathrm{C}$. Even though the specific surface areas of the catalyst- 1 and catalyst- 2 were similar, catalyst- 2 had more active centers after sulfonation.

\section{FT-IR}

The infrared spectra of the carbonized product at $550{ }^{\circ} \mathrm{C}$ and 550 -catalyst- 1 correspond to Figs. $4 \mathrm{a}$ and $4 \mathrm{~b}$, respectively. The peaks at 3432 and $3422 \mathrm{~cm}^{-1}$ were ascribed to the stretching vibration of $\mathrm{O}-\mathrm{H}$, and the peaks at 1630 and $1616 \mathrm{~cm}^{-1}$ were assigned to the $\mathrm{C}=\mathrm{C}$ vibration on the aromatic ring. The adsorption bands of carbonized product at $2921 \mathrm{~cm}^{-1}$ can be attributed to the C-H stretching vibration of saturated hydrocarbon, and the strong peak at $503 \mathrm{~cm}^{-1}$ was due to the presence of magnesium oxide in the carbonized product. In Fig. 3b, the characteristic peak of $\mathrm{SO}_{3} \mathrm{H}$ functional groups appeared at 1182 and $1037 \mathrm{~cm}^{-1}$, and the characteristic peak of C-S appeared at $622 \mathrm{~cm}^{-1}$, which demonstrated that sulfonation successfully connected $\mathrm{SO}_{3} \mathrm{H}$ functional groups to the structure of polycyclic aromatic hydrocarbons (PAHs). The intensity of $\mathrm{C}=\mathrm{C}$ vibration after sulfonation was clearly enhanced, which indicated that further polycondensation occurred during the sulfonation of carbonized products.

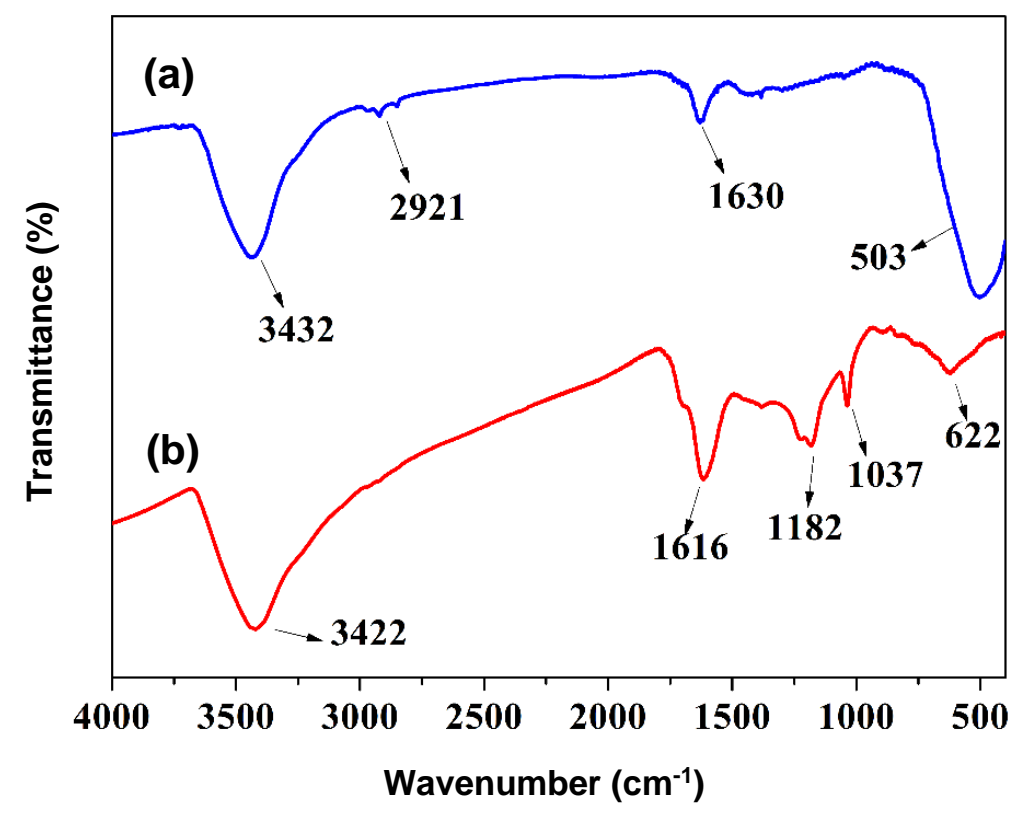

Fig. 4. (a) FT-IR spectra of carbonized product and (b) 550-catalyst-1

\section{XRD}

Figure 5a shows that diffraction peaks of the mixture of ET and $\mathrm{Mg}(\mathrm{OH})_{2}$ at 18.40 , $32.72,37.86,50.66,58.56,62.02,68.14$, and $71.98^{\circ}$ were consistent with the XRD pattern of $\mathrm{Mg}(\mathrm{OH})_{2}$. Taglieri et al. (2015) indicated that the diffraction peaks of ET were covered by the strong diffraction peaks of $\mathrm{Mg}(\mathrm{OH})_{2}$. Figure $5 \mathrm{~b}$ shows that the diffraction peaks of 
carbonized product appeared at 36.98, 42.77, 62.13, 74.22, and 78.29 ${ }^{\circ}$, which were consistent with the XRD pattern of $\mathrm{MgO}$ (Huang et al. 2005). It was shown that $\mathrm{MgO}$ was the product of the decomposition of $\mathrm{Mg}(\mathrm{OH})_{2}$ at high temperature. There were no other diffraction peaks in Fig. 5b, indicating that the peaks of catalyst matrix were concealed by the strong diffraction peaks of $\mathrm{MgO}$. The diffraction peaks of 550-catalyst-1 are shown in Fig. 5c. There was a broad diffraction peak at 20 to $30^{\circ}$, illustrating that the 550-catalyst1 was an amorphous structure arranged at random (Yu et al. 2011). Moreover, no diffraction peaks of $\mathrm{MgO}$ were found in Fig. 5c, demonstrating that the template was completely removed.

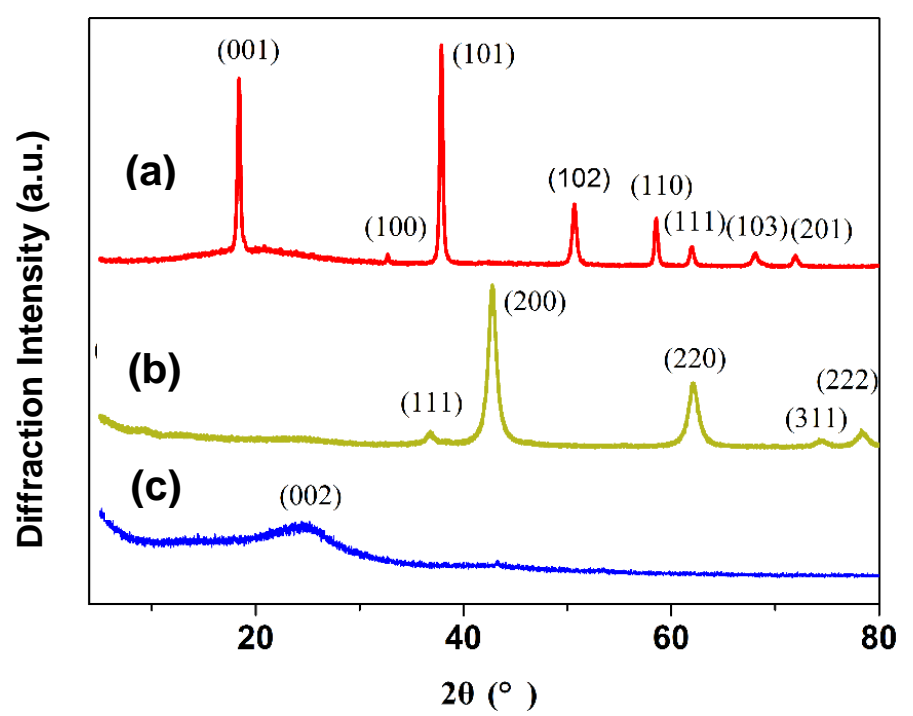

Fig. 5. (a) XRD patterns of the mixture of ET and $\mathrm{Mg}(\mathrm{OH})_{2}$, (b) carbonized product, and (c) 550catalyst-1

\section{The Morphology of 550-Catalyst-1}

The TEM images of acicular $\mathrm{Mg}(\mathrm{OH})_{2}$ and 550-catalyst-1 are shown in Fig. 6a and $6 b$, respectively.

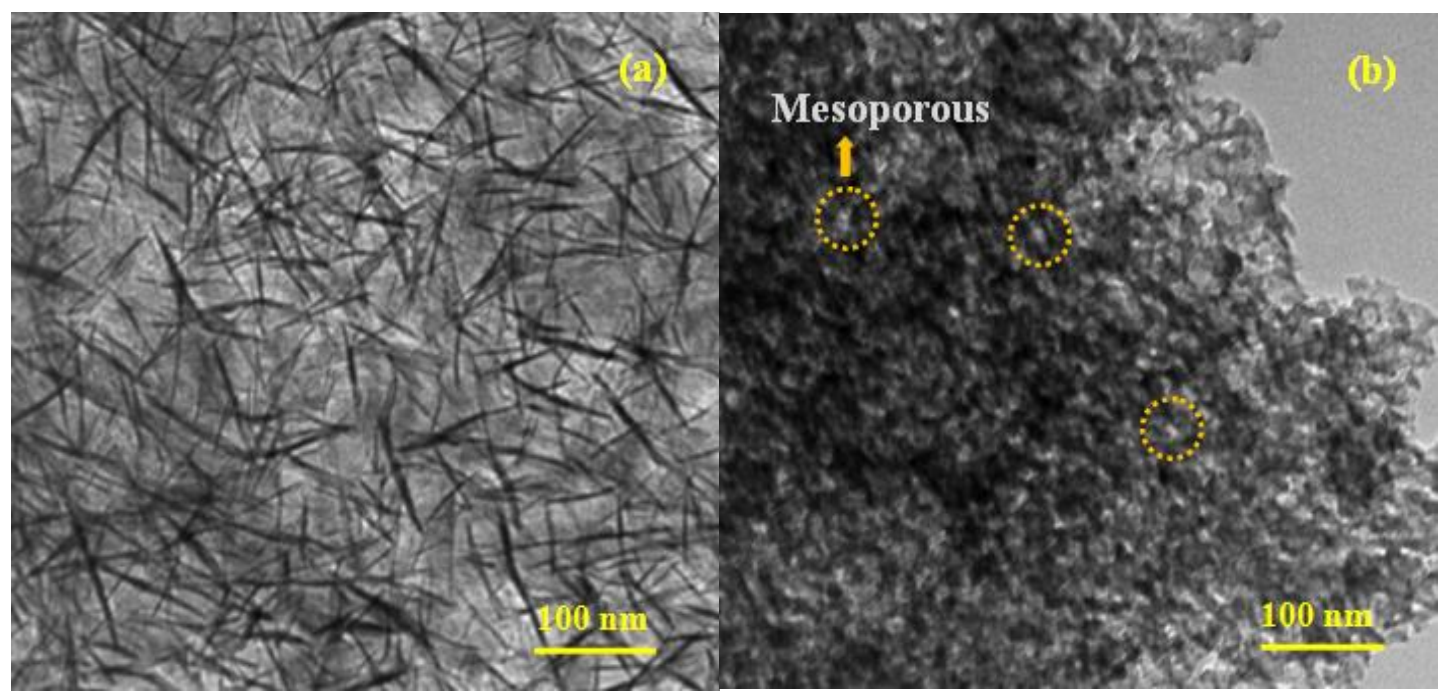

Fig. 6. TEM images of a) acicular $\mathrm{Mg}(\mathrm{OH})_{2}$, and b) 550-catalyst-1 
The acicular $\mathrm{Mg}(\mathrm{OH})_{2}$ was 50 to $100 \mathrm{~nm}$ in length and 3 to $5 \mathrm{~nm}$ in diameter, showing a disordered interlaced distribution. In the process of the carbonization at high temperature, $\mathrm{Mg}(\mathrm{OH})_{2}$ was converted into $\mathrm{MgO}$, but acicular morphology was retained (Qiu et al. 2003). After dissolving $\mathrm{MgO}$ in the sulfonation reaction, the morphology of acicular $\mathrm{MgO}$ was copied in the pores.

\section{The Stability of the Catalyst}

The authors tested the stability of 550-catalyst- 1 under the optimum reaction conditions, as shown in Fig. 7. The 550-catalyst-1 was washed three times with hot ethanol and hot water, dried at $80{ }^{\circ} \mathrm{C}$ for $12 \mathrm{~h}$, and then weighed for the next experiment. The conversion of fructose, 5-HMF yield, and the selectivity of 5-HMF after 5 cycles were investigated. The results are shown in Fig. 7. The conversion of fructose, the yield of 5$\mathrm{HMF}$, and the selectivity of 5-HMF decreased from $97.5 \%, 80.1 \%$, and $82.2 \%$ to $93.6 \%$, $74.3 \%$, and $79.4 \%$, respectively. The catalytic activity did not decrease obviously, which showed that 550-catalyst-1 had good stability. Because the sulfonic acid groups were connected to the polyaromatic skeleton by chemical bonds, it did not easily fall off in the reaction.

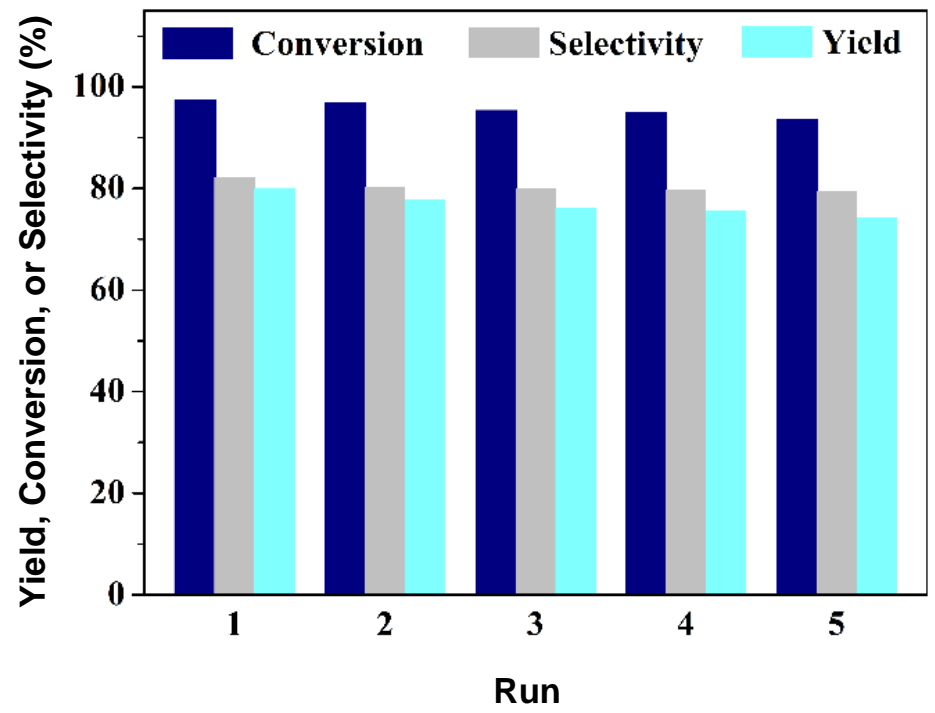

Fig. 7. Recyclability experiments of 550-catalyst-1

\section{CONCLUSIONS}

1. The specific surface area of the catalyst obtained by the one-step method was larger than that of the two-step method, which indicated that the simultaneous sulfonation and the removal of template can protect the mesoporous structure from damage to a certain extent.

2. When the mass ratio of ET to acicular magnesium hydroxide was $1: 3$, the specific surface area of the catalyst was $446.5 \mathrm{~m}^{2} / \mathrm{g}$, the acid density was $4.68 \mathrm{mmol} / \mathrm{g}$, and the average pore diameter was $3.5 \mathrm{~nm}$. When the catalyst was applied in the dehydration of fructose, $97.5 \%$ fructose conversion and $80.1 \%$ 5-HMF yield can be obtained. The catalyst had good stability. 
3. The preparation of acicular mesoporous char sulfonic acid by the simple one-step method using inexpensive ethylene tar as carbon source has a good prospect.

\section{ACKNOWLEDGEMENTS}

This work was supported by the "Thirteen Five Years" Science and Technology Project of the Education Department of Jilin Province (No. JJKH20190835KJ), the Science and Technology Research Project of Jilin Institute of Chemical Technology (No. 202020) and the Doctoral Initiation Fund Project of Jilin Institute of Chemical Technology (No. 2020006).

\section{REFERENCES CITED}

Budarin, V., Clark, J. H., Hardy, J. J. E., Luque, R., Milkowski, K., Tavener, S. J., and Wilson, A. J. (2006). "Starbons: New starch-derived mesoporous carbonaceous materials with tunable properties," Angewandte Chemie International Edition 45(23), 3782-3786. DOI: 10.1002/anie.200600460

Daengprasert, W., Boonnoun, P., Laosiripojana, N., Goto, M., and Shotipruk, A. (2011). "Application of sulfonated carbon-based catalyst for solvothermal conversion of cassava waste to hydroxymethylfurfural and furfural," Industrial \& Engineering Chemistry Research 50(13), 7903-7910. DOI: 10.1021/ie102487w

Dutta, S., De, S., and Saha, B. (2013). "Advances in biomass transformation to 5hydroxymethylfurfural and mechanistic aspects," Biomass and Bioenergy 55, 355369. DOI: 10.1016/j.biombioe.2013.02.008

Farabi, M. S. A., Ibrahim, M. L., Rashid, U., and Taufiq-Yap, Y. H. (2019). "Esterification of palm fatty acid distillate using sulfonated carbon-based catalyst derived from palm kernel shell and bamboo," Energy Conversion and Management 181, 562-570. DOI: 10.1016/j.enconman.2018.12.033

Ge, C. Z., Yang, H. X., Wang, J. T., Qiao, W. M., Long, D. H., and Ling, L. C. (2016). "Highly effective utilization of ethylene tar for mesophase development via a molecular fractionation process," RSC Advances 6(1), 796-804. DOI: 10.1039/C5RA20651K

Hara, M., Yoshida, T., Takagaki, A., Takata, T., Kondoet, J. N., Hayashi, S., and Domen, K. (2004). "A carbon material as a strong protonic acid," Angewandte Chemie International Edition 43(22), 3015-3018. DOI: 10.1002/anie.200453947

Hayashi, E., Yamaguchi, Y., Kamata, K., Tsunoda, N., Kumagai, Y., Oba, F., and Hara, M. (2019). "Effect of $\mathrm{MnO}_{2}$ crystal structure on aerobic oxidation of 5-hydroxymethylfurfural to 2,5-furandicarboxylic acid," Journal of the American Chemical Society 141(2), 890-900. DOI: 10.1021/jacs.8b09917

Huang, L., Li, D. Q., Lin, Y. J., Wei, M., Evans, D. G., and Duan, X. J. (2005). "Controllable preparation of Nano-MgO and investigation of its bactericidal properties," Journal of Inorganic Biochemistry 99(5), 986-993. DOI: 10.1016/j.jinorgbio.2004.12.022

Janaun, J., and Ellis, N. (2011). "Role of silica template in the preparation of sulfonated mesoporous carbon catalysts," Applied Catalysis A: General 394(1), 25-31. DOI: 10.1016/j.apcata.2010.12.016 
Karimi, B., Mirzaei, H. M., Behzadnia, H., and Vali, H. (2015). "Novel ordered mesoporous carbon-based sulfonic acid as an efficient catalyst in the selective dehydration of fructose into 5-HMF: The role of solvent and surface chemistry," ACS Applied Materials \& Interfaces 7(34), 19050-19059. DOI: 10.1021/acsami.5b03985

Kitano, M., Arai, K., Kodama, A., Kousaka, T., Nakajima, K., Hayashi, S., and Hara, M. (2009). "Preparation of a sulfonated porous carbon catalyst with high specific surface area," Catalysis Letters 131(1), 242-249. DOI: 10.1007/s10562-009-0062-4

Liguori, F., Barbaro, P., and Calisi, N. (2019). "Continuous-flow oxidation of HMF to FDCA by resin-supported platinum catalysts in neat water," ChemSusChem 12(12), 2558-2563. DOI: 10.1002/cssc.201900833

Malins, K., Kampars, V., Brinks, J., Neibolte, I., and Murnieks, R. (2015). "Synthesis of activated carbon-based heterogenous acid catalyst for biodiesel preparation," Applied Catalysis B: Environmental 176-177, 553-558. DOI: 10.1016/j.apcatb.2015.04.043

Peng, L., Philippaerts, A., Ke, X., Noyen, J. V., Clippel, F. D., Tendeloo, G. V., Jacobs, P. A., and Sels, B. F. (2010). "Preparation of sulfonated ordered mesoporpus carbon and its use for the esterification of fatty acids," Catalysis Today 150(1-2), 140-146. DOI: 10.1016/j.cattod.2009.07.066

Qiu, L. Z., Xie, R. C., Ding, P., and Qu, B. J. (2003). "Preparation and characterization of $\mathrm{Mg}(\mathrm{OH})_{2}$ nanoparticles and flame-retardant property of its nanocomposites with EVA," Composite Structures 62(3-4), 391-395. DOI: 10.1016/j.compstruct.2003.09.010

Rosatella, A. A., Simeonov, S. P., Frade, R. F. M., and Afonso, C. A. M. (2011). "5Hydroxymethylfurfural (HMF) as a building block platform: Biological properties, synthesis and synthetic applications," Green Chemistry 13(4), 754-793. DOI: 10.1039/C0GC00401D

Saha, B., and Abu-Omar, M. M. (2014). "Advances in 5-hydroxymethylfurfural production from biomass in biphasic solvents," Green Chemistry 16(1), 24-38. DOI: 10.1039/C3GC41324A

Shimizu, K., Uozumi, R., and Satsuma, A. (2009). "Enhanced production of hydroxymethylfurfural from fructose with solid acid catalysts by simple water removal methods," Catalysis Communications 10(14), 1849-1853. DOI: 10.1016/j.catcom.2009.06.012

Taglieri, G., Felice, B., Daniele, V., and Ferrante, F. (2015). " $\mathrm{Mg}(\mathrm{OH})_{2}$ nanoparticles produced at room temperature by an innovative, facile, and scalable synthesis route," Journal of Nanoparticle Research 17, Article number 411. DOI: 10.1007/s11051015-3212-1

Tanemura, K., Suzuki, T., Nishida, Y., and Horaguchi, T. (2011). "Synthesis of the sulfonated condensed polynuclear aromatic (S-COPNA) resins as strong protonic acids," Tetrahedron 67(6), 1314-1319. DOI: 10.1016/j.tet.2010.11.077

Tanemura, K., Suzuki, T., Nishida, Y., and Horaguchi, T. (2012). "Synthesis of the strongly acidic sulfonated condensed polynuclear aromatic (S-COPNA) resins using aromatic aldehydes as cross-linking agents," Polymer Bulletin 68, 705-719. DOI: 10.1007/s00289-011-0574-0

Thananatthanachon, T., and Rauchfuss, T. B. (2010). "Efficient production of the liquid fuel 2,5-dimethylfuran from fructose using formic acid as a reagent," Angewandte Chemie International Edition 49(37), 6616-6618. DOI: 10.1002/anie.201002267 
Toda, M., Takagaki, A., Okamura, M., Kondo, J. N., Hayashi, S., Domen, K., and Hara, M. (2005). "Biodiesel made with sugar catalyst," Nature 438, 178. DOI: $10.1038 / 438178 \mathrm{a}$

Wang, H., Zhu, C., Li, D., Liu, Q., Tan, J., Wang, C., Cai, C., and Ma, L. (2019). "Recent advances in catalytic conversion of biomass to 5-hydroxymethylfurfural and 2, 5dimethylfuran," Renewable and Sustainable Energy Reviews 103, 227-247. DOI: 10.1016/j.rser.2018.12.010

Wang, J., Xu, W., Ren, J., Liu, X., Lu, G., and Wang, Y. (2011). “Efficient catalytic conversion of fructose into hydroxymethylfurfural by a novel carbon-based solid acid," Green Chemistry 13(10), 2678-2681. DOI: 10.1039/C1GC15306D

Yang, F., Liu, Q., Bai, X., and Du, Y. (2010). "Conversion of biomass into 5hydroxymethylfurfural using solid acid catalyst," Bioresource Technology 102(3), 3424-3429. DOI: 10.1016/j.biortech.2010.10.023

Yu, J. T., Dehkhoda, A. M., and Ellis, N. (2011). "Development of biochar-based catalyst for transesterification of canola oil," Energy \& Fuels 25(1), 337-344. DOI: 10.1021/ef100977d

Zhang, J., Wu, S., Li, B., and Zhang, H. (2012). "Advances in the catalytic production of valuable levulinic acid derivatives," ChemCatChem 4(9), 1230-1237. DOI: W10.1002/cctc.201200113

Zhang, W., Huang, Z., Cao, Z., Kang, F., and Yang, Y. (2012). "A novel mesoporous carbon with straight tunnel-like pore structure for high rate electrochemical capacitors," Journal of Power Sources 204, 230-235. DOI: 10.1016/j.jpowsour.2011.12.054

Zhang, M., Sun, A., Meng, Y., Wang, L., Jiang, H., and Li, G. (2015). "High activity ordered mesoporous carbon-based solid acid catalyst for the esterification of free fatty acids," Microporous and Mesoporous Materials 204, 210-217. DOI: 10.1016/j.micromeso.2014.11.027

Article submitted: July 24, 2020; Peer review completed: October 17, 2020; Revised version received: October 31 2020; Accepted: November 1, 2020; Published: November $18,2020$.

DOI: 10.15376/biores.16.1.324-338 


\section{APPENDIX}

\section{SUPPLEMENTARY INFORMATION}

\section{Determination of Acid Density of Catalyst}

The standard back acid-base titration method was used to quantify the acid density of the catalysts. The catalyst was pre-dried in a vacuum drying oven at $100{ }^{\circ} \mathrm{C}$ for $2 \mathrm{~h}$ prior to analysis, then $1.00 \mathrm{~g}$ catalyst was soaked in $50 \mathrm{~mL}$ of $0.1 \mathrm{M} \mathrm{NaOH}$ solution $24 \mathrm{~h}$ before back-titrating with $0.1 \mathrm{M} \mathrm{HCl}$ solution. The $\mathrm{NaOH}$ solution and $\mathrm{HCl}$ solution used in the experiment were calibrated. Acid density of catalyst was measured three times, then the results were averaged.

\section{Thermogravimetric Analysis (TGA)}

Thermal stability of catalysts was measured using a Q5000 instrument, under flowing nitrogen with a heating rate of $10{ }^{\circ} \mathrm{C} / \mathrm{min}$ from 25 to $800{ }^{\circ} \mathrm{C}$. The thermogravimetric analysis of 550-catalyst-1 is presented in Fig. S1. It can be seen from Fig. S1 that the weight loss in the temperature range of 70 to $110^{\circ} \mathrm{C}$ may have been caused by the removal of water adsorbed on the catalyst surface. The weight loss tended to be stable between $110^{\circ} \mathrm{C}$ and $320^{\circ} \mathrm{C}$. After $320^{\circ} \mathrm{C}$, the apparent weight loss of 550-catalyst1 was observed due to the decomposition. This illustrated that 550-catalyst- 1 can maintain good thermal stability at temperatures below $320^{\circ} \mathrm{C}$.

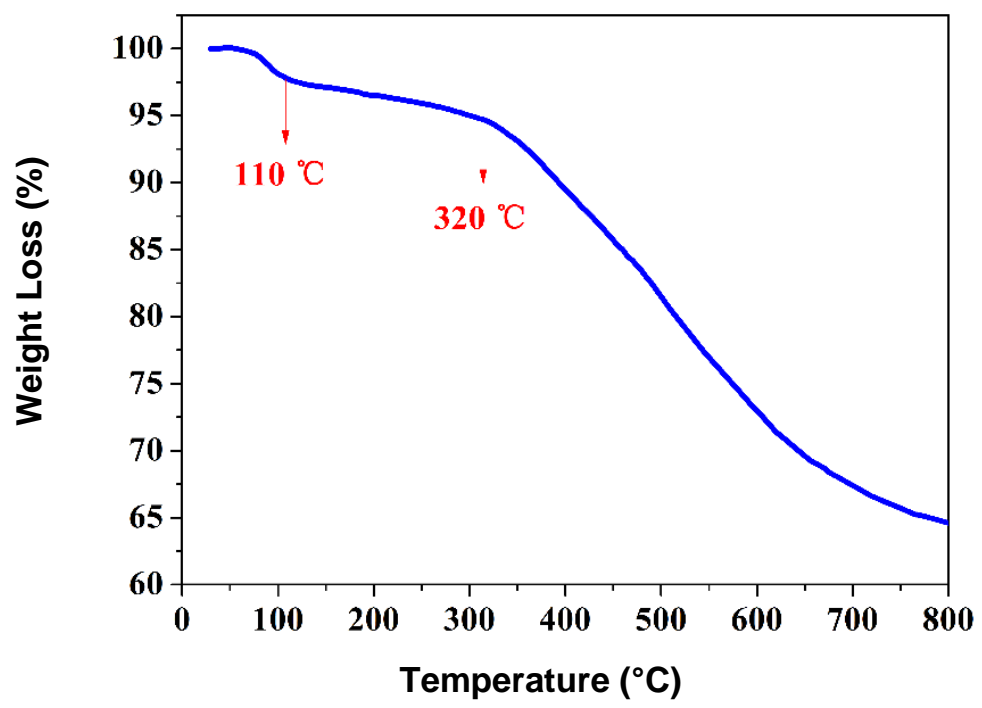

Fig. S1. TGA curves of 550-catalyst-1 